\title{
An Empirical Study of Banking Fragility in China Based on VAR Model
}

\author{
Xu Lingjuan, Li Qian, and Wang Yanjun
}

\begin{abstract}
On account of its fragility, the banking system is more vulnerable to crisis, which if accumulated to a certain extent will become a financial or even economic crisis. Beginning with the empirical research concerning fragility, this paper analyzes to which extent the fragility of our banking system has reached as well as what and how this fragility has been led to.In addition, a VAR model is used to demonstrate the relationship between the fragility and its contributing factors, and finally deduce the seasonal tendency of the fragility of our banking system.
\end{abstract}

Index Terms - Banking system, fragility, VAR model.

\section{INTRODUCTION}

The healthy development of the financial system plays an important role in the national economy. As the most important part in the financial system, the banking system's steady and healthy development has the vital role in the steady growth of national economy. The strength of banking fragility is related to China's financial stability and financial development. Through analyzing the fragility of banking system, we will find out the improvement factor of banking fragility which can improve the ability of banks to resist the risk, and contribute to the development of macro economy.

There are a lot of calculation and demonstration for the fragility of banking system at home and abroad. Most of early paper were based on qualitative research, and in recent 20 years paper are more emphasis on quantitative analysis. The important quantitative analysis include Frankel and Rose's Probit model, SachsTomell and Velasco's STV model, and Kaminsky's Signal Analysis Method. Among the domestic scholars, Fan Hongbo (2004) used the Logistic model to analyze the fragility of the state-owned commercial banking system. Wen Fenghua (2012) chose 13 core indicators and used multivariate factor analysis to study the financial fragility of recent 11 years; Based on Chinese related data from 1990 to 2011, $\mathrm{Xu} \mathrm{Lu}$ and Qian Xuesong (2013) structured a multiple regression equation to examine the effect of the credit boom factors on banking fragility.

Overall, these analysis deepens our understanding of the

Manuscript received June 24, 2016; revised August 23, 2016. This work was supported in part by College of Economics and Management, Nanjing University of Aeronautics and Astronautics.

The authors are with the College of Economics and Management, Nanjing University of Aeronautics and Astronautics, Nanjing, Jiangsu, 210016, China (e-mail: linda_xu@nuaa.edu.cn, nuaalq@126.com, 578907314@qq.com). fragility of China's banking system, including the reason and the relationship, but these studies also have the following deficiencies: Firstly, since China's economic environment has undergone significant changes in recent years, and banking situation changed a lot, the "0-1" form in Logistic model which is widely used in previous studies does not reflect the fragility of banking system in china. Secondly, there is a dynamic stability hypothesis in traditional econometric methods, while in fact the economy time alignment is generally non-stable. So it easily leads to "spurious regression", while Granger causality test can cover the shortage. Thirdly, different factors which affect banking fragility will also influence each other, and may have a lag effect, but the former did not take this into consideration.

In this paper, the author uses VAR model to analyze the fragility of China's banking system based on relevant data from 2004 to 2015 Banking fragility is rooted in high debt management, a maturity mismatch between assets and liabilities, the information asymmetry between supply and demand, and the periodic behavior caused by the principal-agent problems [1], [2].

\section{QUESTIONS AND HyPOTHESES}

Consequently, on the basis of previous studies, the author selects beta coefficients which is used to reflect banking fragility, then establishes a VAR model to analyze the relationship between banking fragility and the contributing factors. After that, impulse response function is used to analyze the degree of each variable's influence on banking fragility. Finally, the author uses Granger causality test and variance decomposition to get the contribution degree of the variables on banking fragility, in order to know banking fragility's characteristics and trend from 2004 to 2015.

In this way, this paper not only avoid possible "pseudo regression problems" and the irrational simple weighted average, but also consider the lag effect, because VAR model for dealing with dynamic system is more effective.

After considering the data availability, previous research and the degree among generality, the existing analysis, the author chooses macro and micro variables to measure and analyze.

On the one hand, deterioration of the macro economic variables will increase the fragility of the banking system, and fragility will further accumulate the economic risk. For example, when CPI is maintained at a high level, high inflation rate makes the principal shrink. Then people will be more inclined to the investment which has high rate of return instead of saving. More seriously, it will cause a bank run and increase the fragility of banking system.

On the other hand, micro variables will also increase the 
fragility of banking system. For example, if the credit quality has problems, high non-performing loan ratios will increase banking fragility; Similarly, in the cases of economic stagnation or asset bubbles, higher asset-liability ratio cannot turn into profits, but accumulate the risk.

\section{INDEX SELECTION}

On the basis of this analysis, we choose the following index and establish a model. Because the banking fragility (CR) is very difficult to define, this article wants to construct a virtual beta coefficient to measure the banking fragility in order to avoid the subjectivity of virtual variable method. The coefficient is based on the CAPM theory by the 180 financial index and the shanghai composite index. According to the

$$
\begin{aligned}
& \text { CAPM [3], } E\left(R_{i}\right)=R_{F}+\left[E\left(R_{M}\right)-R_{F}\right] \beta_{i} \\
& \beta_{i}=\operatorname{Cov}\left(R_{i}, R_{M}\right) / \sigma_{M}^{2}, \text { it is used to measure the }
\end{aligned}
$$
relative market risk of different assets. Beta value and the risk change are in the same direction. In this paper, Ri said the 180 financial index returns, $\sigma_{M}^{2}$ said the variance of returns of Shanghai Composite Index. There are two reasons for building the index: First, constituent stocks of 180 financial Index contain almost all of the listed banks in China, which has very high representative on banks; secondly, the beta coefficient measures degree of dependence between returns of some risk assets and the market, and the volatility of yield rate also can describe risk. In addition, risk accumulation may lead to fragility, so banking fragility can be explained by coefficient of beta. The specific rules are as follows:

1) When bet $a>1$, the returns of banking system change faster than market returns, so the banking fragility is higher.

2) When bet $a<1$, it changes slower than market returns, so the banking fragility is relatively lower.

3) When bet $a=1$, the returns of banking system and market change synchronously, banking fragility is also changes synchronously.

It is worth pointing out that, the market return depends on the operation of the national economy. So the banking fragility is a relative concept, which says the speed of risk accumulation relative to the development of the national economy. When the economy fluctuates severely, the smaller beta coefficient is helpful to resist market risk. But when the economy is good, the smaller beta coefficient hinders income increase and reflects the risk increase.

Therefore, according to the asset portfolio theory, the author makes 180 financial index returns as a portfolio's return rate, the Shanghai composite index returns as the market portfolio returns, so it can be constructed beta coefficients of 180 financial index related to banking fragility.

\begin{tabular}{|c|c|c|}
\hline & Variables & The meanings of variables \\
\hline \multirow{5}{*}{ Macro Variables } & CPI & $\begin{array}{l}\text { CPI essentially reflects a potential currency risk. For the bank, if the bank loan } \\
\text { difference is relatively large, high inflation rate will make the principal shrink. In } \\
\text { addition, many people will choose the investment which has high rate of return } \\
\text { instead of saving. Seriously, it can cause bank run. }\end{array}$ \\
\hline & FER & $\begin{array}{l}\text { Foreign exchange reserves is directly related to import and export trade, and the } \\
\text { bank plays an important role in the import and export trade settlement. }\end{array}$ \\
\hline & ER & $\begin{array}{l}\text { Exchange rate is directly related to exchange rate risk of the bank; in addition, if } \\
\text { exchange rate changes too far, it will make all kinds of financial products' price } \\
\text { fluctuate unreasonably, and ultimately it will be reflected in the banking fragility. }\end{array}$ \\
\hline & $\mathrm{M}_{2}$ & $\begin{array}{l}\text { Growth rate of } \mathrm{M}_{2} \text { reflect the trend of monetary policy trends and the situation of } \\
\text { market liquidity, That } \mathrm{M}_{2} \text { and GDP are not equal may reflect the underlying } \\
\text { inflation. }\end{array}$ \\
\hline & QR & $\begin{array}{l}\text { Business climate index reflects the trend of real economic development, but there is } \\
\text { also "safety margin" problem of banks. }\end{array}$ \\
\hline \multirow{3}{*}{ Micro Variables } & ALR & $\begin{array}{l}\text { In the cases of economic stagnation, credit quality problems or asset bubbles, high } \\
\text { asset-liability ratio can not turn into profits, but accumulate the risk. }\end{array}$ \\
\hline & BLR & $\begin{array}{l}\text { The bad loan ratio reflects the credit risk of the bank. High rate of bad loans will } \\
\text { increase supply pressure of the bank credit funds, and also affect the bank operating } \\
\text { efficiency. }\end{array}$ \\
\hline & LDR & $\begin{array}{l}\text { Loan to deposit ratio shows the ability that banks raise deposits to meet loan. If this } \\
\text { value is too high, banks could face shocks of liquidity demand. }\end{array}$ \\
\hline
\end{tabular}

TABLE I: THE MEANINGS OF VARIABLES

According to the IMF research [4], "Basel III" as well as the availability of data, other indicators can be divided into two categories of macro and micro indicators. Among them, there are CPI, M2 growth rate, change rate of enterprise boom index $(\mathrm{QR})$, the growth rate of foreign exchange reserves (FER) and the RMB exchange rate against the dollar (ER). The micro index which is the evaluation index of the banking industry mainly include: bad loan ratio (BLR), loan to deposit ratio (LDR) and asset-liability ratio (ALR). The meaning of each index is shown in Table I.

In this part, all data come from the National Bureau of Statistics website, the people's Bank of China website, and
Chinese Banking Regulatory Commission Web site.

\section{MODELING AND ANALYSIS OF RESUlts}

\section{A. Impulse Response Function of Banking Fragility}

The relationship between the banking fragility and its contributing factors is a dynamic system. The effects of various economic variables on banking fragility are persistent and restrict each other. According to this characteristic, this paper chooses VAR model [5] to describe the relationship between the banking fragility and its 
contributing factors. VAR model is relatively easy to perform which can be used to analyze and predict multiple related economic indicators. To explain the effects of various economic shocks on economic variables, this model is usually used to predict correlated time series systems and analyze dynamical impact of random perturbations on variable system.

The mathematical expression of VAR model is:

$$
y_{t}=\Phi_{1} y_{t-1}+\cdots+\Phi_{p} y_{t-p}+H x_{t}+\varepsilon_{t}, t=1,2, \cdots, T
$$

In this formula: $y_{t}$ is the column vector of $\mathrm{k}$ dimension endogenous variable ; $x_{t}$ is the column vector of d dimension exogenous variable, $\mathrm{p}$ is the lag order number, $\mathrm{t}$ is the number of sample. $\Phi$, and $\mathrm{H}$ are the coefficient matrix to be estimated, $\varepsilon_{t}$ is the column vector of $k$ dimension disturbance .

We use the AIC information criterion to select the lag order of VAR model. According to the results of Table II, we should establish the VAR (1) model.

TABLE II: LAG ORDER SELECTION

\begin{tabular}{|c|c|c|c|c|c|c|}
\hline Lag & $\log L$ & LR & FPE & $\mathrm{AIC}$ & $\mathrm{SC}$ & HQ \\
\hline 0 & 546.6789 & NA & $1.69 \mathrm{e}-28$ & -38.40564 & -37.97743 & -38.27473 \\
\hline 1 & 824.7950 & $367.5778^{*}$ & $1.75 \mathrm{e}-34^{*}$ & $-52.48535^{*}$ & $-48.20327^{*}$ & $-51.17628^{*}$ \\
\hline \multicolumn{7}{|c|}{ TABLE III: AR ROOTS TABLE } \\
\hline \multicolumn{4}{|c|}{ Root } & \multicolumn{3}{|c|}{ Modulus } \\
\hline \multicolumn{4}{|c|}{0.898039} & \multicolumn{3}{|c|}{0.898039} \\
\hline \multicolumn{4}{|c|}{$0.810987-0.197725 \mathrm{i}$} & \multicolumn{3}{|c|}{0.834742} \\
\hline \multicolumn{4}{|c|}{$0.810987+0.197725 \mathrm{i}$} & \multicolumn{3}{|c|}{0.834742} \\
\hline \multicolumn{4}{|c|}{$0.629587-0.383977 \mathrm{i}$} & \multicolumn{3}{|c|}{0.737440} \\
\hline \multicolumn{4}{|c|}{$0.629587+0.383977 \mathrm{i}$} & \multicolumn{3}{|c|}{0.737440} \\
\hline \multicolumn{4}{|c|}{$-0.065048-0.438418 \mathrm{i}$} & \multicolumn{3}{|c|}{0.443218} \\
\hline \multicolumn{4}{|c|}{$-0.065048+0.438418 \mathrm{i}$} & \multicolumn{3}{|c|}{0.443218} \\
\hline \multicolumn{4}{|c|}{$0.101456-0.186676 \mathrm{i}$} & \multicolumn{3}{|c|}{0.212465} \\
\hline \multicolumn{3}{|c|}{$0.101456+0.186676 \mathrm{i}$} & & \multicolumn{3}{|c|}{0.212465} \\
\hline
\end{tabular}

After the operation,specific expansion model of VAR(1) is:

$$
y_{t}=\left(C R_{t}, C P I_{t}, F E R_{t}, E R_{t}, M_{2 t}, Q R_{t}, A L R_{t}, B L R_{t}, L D R_{t}\right)^{T}
$$

$\mathrm{p}=1, \mathrm{~T}=29$. The CR equation's goodness of fit $\mathrm{R} 2=0.89$.

AR test results of VAR (1) show that all the modulus of eigenvalues' reciprocal are less than 1 , which is located in the unit circle. So the model is stable, and the impulse response function and residual decomposition will be effective. Therefore, next we will establish the impulse response function. The function is to analyze dynamic effect when an error changes, or the model is affected. In this paper we use this method to analyze characteristics that various economic variables affect banking fragility. Based on the VAR (1) model, impulse response function of the banking fragility are shown in Fig. 1. To analyze the impact of factors on banking fragility, all the diagrams are accumulative responses. Solid line in the figure represents the practical impulse response function, and dashed line represents the fluctuation of plus or minus 2 standard deviation.

For purposes of analysis, the figures can be labeled as

1.1-1.8 in turn from left to right, top to bottom.

Fig. 1.1 shows the reaction about CPI on banking fragility. When CPI is given a positive impact, beta coefficient gradually increases before the 12 stage, then stabilizes at a positive value. It shows that when CPI increases, it is good for banks to avoid risk under the circumstances of better economic situation. That is to say, it will comply with the economic situation.

Fig. 1.2 shows the reaction about FER on banking fragility. When FER is given a positive impact, the beta coefficient is basically stable at a low and negative level before 12 stage. In the long term, the effect will vanish. The impact of foreign exchange on banking fragility is "comply with the economic situation" and short-term.
Fig. 1.3 shows the reaction about ER to banking fragility. When ER is given a positive impact, beta coefficient will be at a positive value. This trend shows that the impact of exchange rate on banking fragility will comply with economy.

Fig. 1.4 shows the reaction about M2 on banking fragility. Positive impact of M2 will make beta coefficient in a backward state. This shows that in the bad economic situation, the increase of M2 will improve the banking fragility.

Enterprise level on beta coefficient has been in a negative state. This shows that when the economic situation is good, the increase of enterprise boom index will increase the banking fragility. It reflects that the relationship between enterprises and banks is becoming more and more closely.

Fig. 1.6 shows the reaction about ALR on banking fragility. When ALR is given a positive impact, the beta coefficient has been in a state of decline. Until the 12 period, it becomes stable at a lower level. This shows that when the bank increased asset-liability ratio, the banking system has strong resistance in the precarious economy. And if national economic situation is good, the risk of banking system will accumulate quickly. This is because in the economic fluctuations, the residents are more willing to put money in the bank, then bank debt increases, so the bank has sufficient funds to deal with market risk. While the economic situation is good, the bank increases the debt actively, then increases the supply of credit beyond the "safety boundary", so risk increases.

Fig. 1.7 shows the reaction about BLR on banking fragility. The beta coefficient is almost zero before 10 stage, then become negative. This shows that the increase of BLR has no impact on banking fragility in the short term. But in the long term, it will buck the economy.

Fig. 1.8 shows the reaction about LDR on banking 
fragility. A positive impact will cause the beta coefficient in the reverse fluctuating state before 4 period, then turn into a positive and stable effect after 12 stage. This shows that the short term impact of LDR on banking fragility is "buck the economy", but in the long term it will comply with the economic situation.

\section{B. Granger Causality Test and Variance Decomposition}

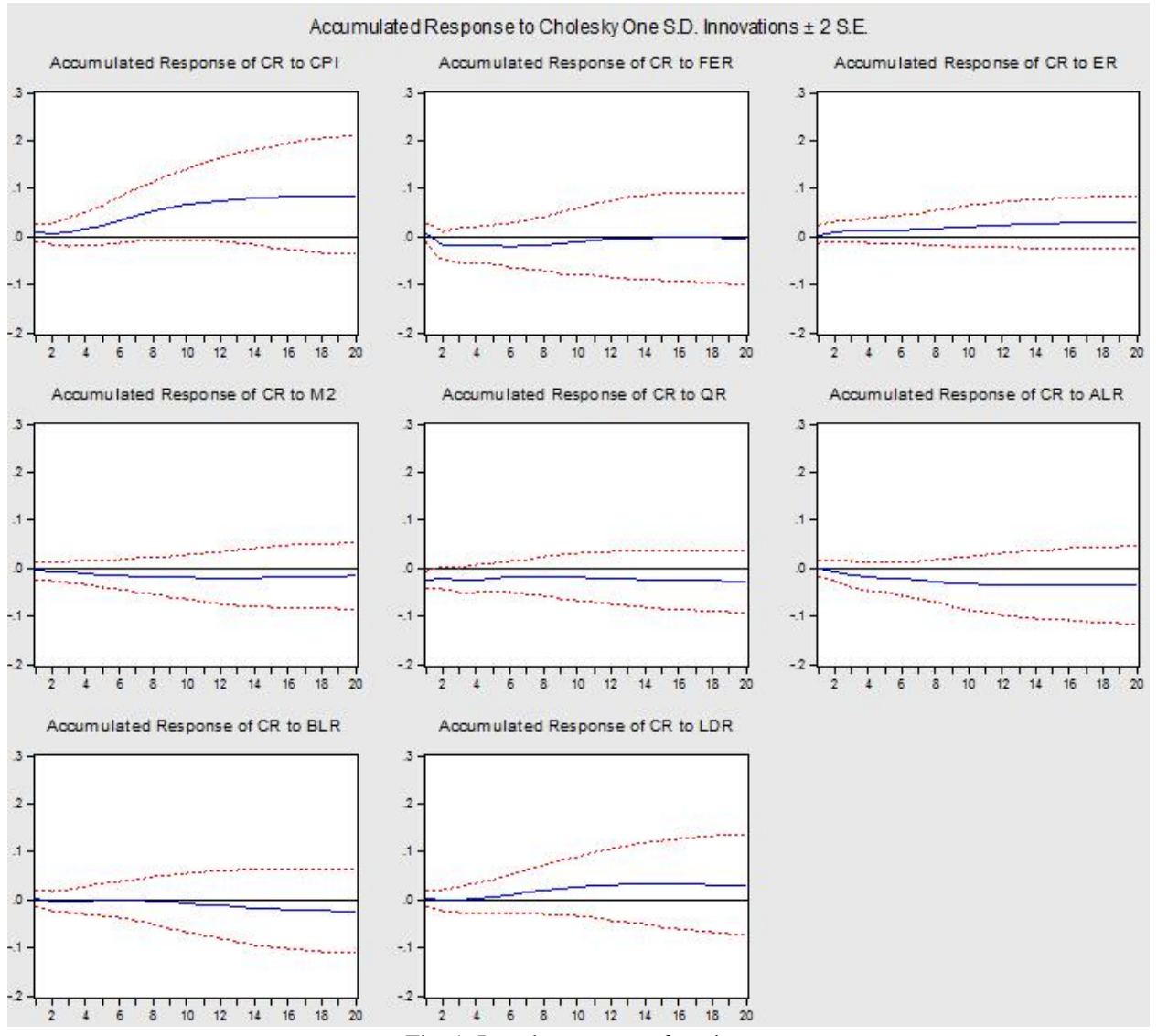

Fig. 1. Impulse response function.

TABLE IV: GRANGER CAUSALITY TEST

\begin{tabular}{cccc}
\hline \hline Excluded & Chi-sq & df & Prob. \\
\hline CPI & 5.884977 & 1 & 0.0153 \\
FER & 5.272290 & 1 & 0.0217 \\
ER & 0.094897 & 1 & 0.7580 \\
M2 & 0.588924 & 1 & 0.4428 \\
QR & 0.371985 & 1 & 0.5419 \\
ALR & 0.822949 & 1 & 0.3643 \\
BLR & 0.934482 & 1 & 0.3337 \\
LDR & 0.308789 & 1 & 0.5784 \\
All & 20.39445 & 8 & 0.0089 \\
\hline \hline
\end{tabular}

Judging from the results, the probability that beta coefficient can not be caused by each variable in combination with Granger is $0.89 \%$. This is a small probability event, and we should reject the hypothesis. So beta coefficient can be caused by each variable in combination with Granger.

In this paper, variance decomposition measures the contribution degree of each variable on the variance of beta, namely the contributing degree of each variable to beta coefficient. Therefore we can use this as the weight of each variable. From Fig. 2, we can see that after 12 period the contributing degree of each variable on beta variance tends to be stable, so the stable variance contributing ratio can be the weight of each variable.

\section{Analysis}

Granger causality test [6] is to show the explanatory power about variables on the beta coefficient and describe the banking fragility reasonably. Based on the VAR (1) model, the results of Granger causality test are shown in Table IV. 
$\mathrm{CR}$ is a virtual beta coefficient, it represents systematic risk. And non-systematic risk is the impact of the real economy on banking fragility. Therefore, the current actual fragility should be a weighted average of the previous period value and the current adjusted value. Expression is as follows:

$$
C R_{t}=\lambda C R_{t-1}+(1-\lambda) \Delta_{t}
$$

$\mathrm{CR}_{\mathrm{t}}$ represents the banking fragility in period t. $\Delta_{t}$ is the adjusted value in period t. $\Delta_{t}$ is composed of 8 other variables, including CPI, FER, ER, M2, QR, ALR, BLR, LDR.

$$
\Delta_{t}=\beta_{1} C P I_{t}+\beta_{2} F E R_{t}+\beta_{3} E R_{t}+\beta_{4} M_{2_{t}}+\beta_{5} Q R_{t}+\beta_{6} A L R_{t}+\beta_{7} B L R_{t}+\beta_{8} L D R_{t}
$$

$\mathrm{CR}$ expression can be obtained in the above two equations. The variance contributing rate tends to be stable after 12 period, so it can be used as each factor's weight. Weight vector is:

beta $=(0.43,0.14,0.17,0.016,0.013,0.14,0.034, \quad 0.021$, $0.036)$

As we can see, FER, CPI and QR which has large variance contributing degree on banking fragility, are respectively $17.1 \%, 13.65 \%$ and $14.29 \%$; and the variance contributing degree of FER on banking fragility is only
$1.3 \%$.

When the data of each variable are standardized, we can get banking fragility simulation chart (Fig. 3).

As can be seen from Fig. 3, the beta coefficient of China's banking industry has greatly changed in 2008 and 2011, which is greater than 1 , or even more than 1.5. This means that when the external macro economic situation changes, it directly affects the fragility of China's banking system and increases the operation risk; in addition, most of the time the beta coefficient in China is less than 1 . This shows that China's banking fragility is relatively independent and its contributing factors of banking fragility are mainly from the banking system; Moreover, beta coefficient which is less than 1 suggests that banking fragility is "buck the economy". Due to prudence principle, the bank increases ability of resistance risk and fragility can be improved in a economic downturn. When the economy is in the upward phase, bank credit can easily cross the"safety margin" [8], so banking fragility accumulates rapidly.

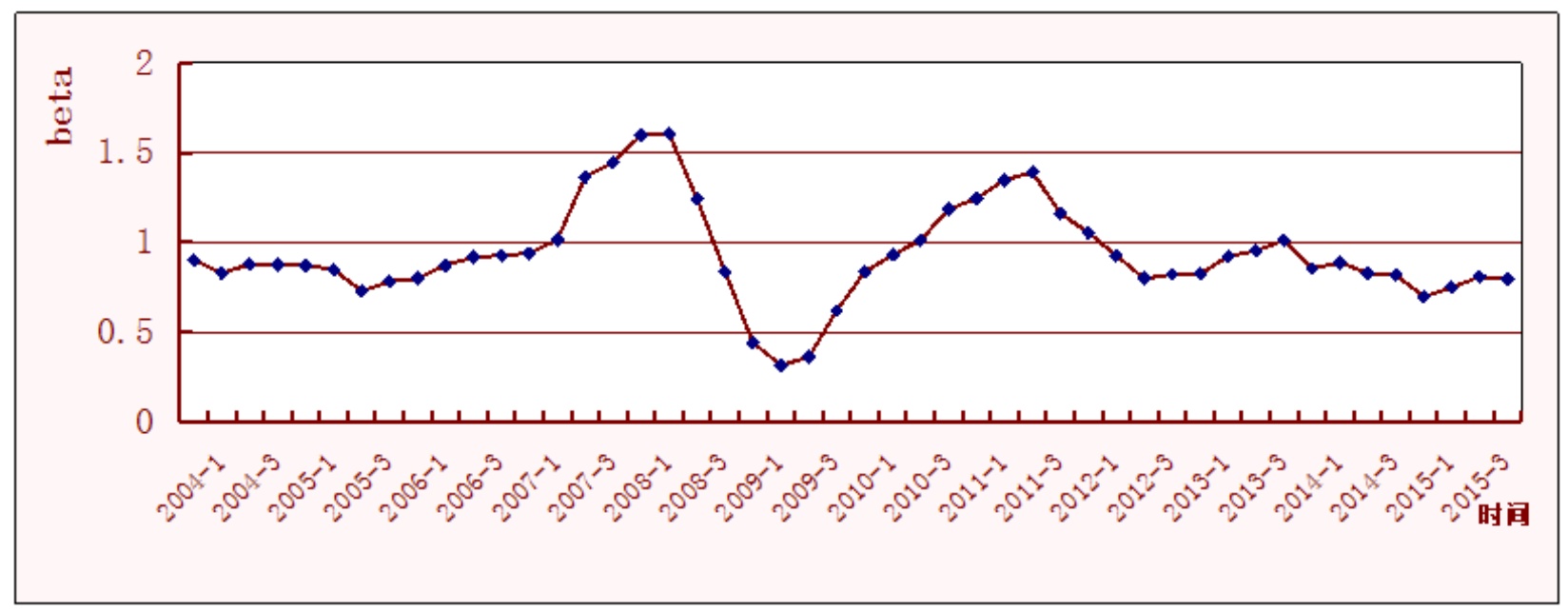

Fig. 3. Banking fragility level trend 2004-2015.

From the trend, China's banking fragility from 2004 to 2015 shows "M" on the morphology. The second quarter of 2009 is in the bottom, and the second quarter of 2008 and the third quarter of 2011 are at two highs. The main changes are as follows:

In 2004-2005, the fragility of China's banking system remained stable, showing a slight downward trend. At this stage, the people's Bank of China invested $\$ 450$ billion into Bank of China and Construction Bank of China, because at that time they played an important role in the bank system of our country, then China's banking system vulnerability has been greatly relieved, so that we can from the figure seen in 2005, China's banking system fragility decreased by a small margin.

(1) In 2006-2008 years, the fragility of China's banking system has generally showed a downward trend after the first rise.

The last two quarters of 2007, the first three quarters of 2008 and 2011, beta coefficient is more than 1, which suggests that banking fragility of 2007-2008 is in a sensitive state.
From a macro point of view, China's economy has large fluctuations in 2007-2008. Inflation pressures continued to accumulate, and CPI reached $8 \%$ in the first quarter of 2008 ; at the same time, because of inflation, the bank deposits showed negative interest rates, so that banks faced difficulties in financing.

From the micro perspective, in the whole year of 2007 and the first half year of 2008 , LDR at about $68 \%$ is relatively high. The deterioration of environment increased the banking fragility. From the beginning of 2007, banking fragility experienced the fluctuation of "roller coaster" type. First of all, the beta coefficient is more than 1 in the last three quarter of 2007, then it is more than 1.5 in the first quarter of 2008, and slumped in the last two quarters of 2008. This phenomenon should be attributed to the macro economic upheaval. In June of 2007, the financial crisis outbroke in USA, and quickly spread to the whole world. In our country, from the end of 2007 to the spring of 2008, inflation has become more and more serious, and the average CPI in this period was $7.76 \%$, significantly speeding up the pace of economic recession. The external environment which 
deteriorated sharply exacerbated the deterioration of banking fragility, and the bank's internal problems can not be ignored. The liquidity ratio of the bank were the lowest level in history, and the serious liquidity risk made the banking fragility worse. Banking fragility has a sharp decline in the last two quarters of 2008 which is mainly due to the decline of non-performing loans, from $5.49 \%$ of the third quarter to $2.42 \%$.

(2) In 2009-2012 years, the fragility of China's banking system has generally showed a downward trend after the first rise.

From 2010 to 2011, banking fragility is on the rise and more than 1 . This can be understood that banking fragility of the phase is sensitive. The main reason is the outbreak of the European debt crisis in 2010, and it brought severe challenges to the development of China's macroeconomic and banking system vulnerability. CPI reached $6.2 \%$ in the third quarter of 2011, and the microscopic indexes--LDR is slightly rising. From the end of 2011, banking fragility is in a state of decline and the beta coefficient is less than 1, which indicates that the banking fragility is improved. Because countries implement a prudent monetary policy, repeatedly raised the deposit reserve ratio and deposit and loan interest rates, making price pressure to slow down, and gradually maintain the basic stability of the general level of prices.

(3) In 2013-2015, the fragility of China's banking system is in a state of fluctuation.

Beta coefficients of this stage are at a level of less than 1 , which shows that under the control of the parties, China's economic situation is relatively stable, the overall situation of the bank is relatively good.

Affected by the slowdown in the domestic economy, some of the customers' funds continued to be tight. And in 2013 the bank overdue loans increased significantly, making the first half of 2013 beta coefficient rose slightly. Faced with this situation, in the first half of the year banks take active measures to prevent potential risks and bad loan disposal, then it effectively guaranteed the controllable risk and the vulnerability can be improved, the beta coefficient showed downward trend. In 2014, Industrial and Commercial Bank of China and other 6 banks approved the implementation of advanced methods of capital management, strengthen the banking industry risk management foundation, reducing the vulnerability of the banking system. In recent years, banking fragility is in the fluctuating adjustment and beta coefficient is less than 1, which indicates that the overall situation is good.

\section{CONCLUSION}

\section{A. According to Different Conditions, Take Different Measures to Improve Banking Fragility}

According to the definition of beta coefficient, lower one can help the bank improve banking fragility in the economic downturn, and higher one can improve its fragility in the economic upturn. Therefore, when banks and regulators draw up management principles on banking fragility, they should follow the operation of the national economy. According to the results of the variance decomposition analysis, when the economy is in the upturn, CPI, FER and QR can be adjusted to increase the beta coefficient. In addition, the adjustment of ER, ALR, BLR and LDR also have certain influence on the beta coefficient. To achieve the desired effect, each variable should be adjusted, and not rely on a single adjustment of a variable. When the economy is down, the beta coefficient should be reduced to improve the banking fragility and the methods should be in contrast in the economic upturn.

\section{B. The Influence on Economic Variables to Banking Fragility has a Different Time Effect}

From the impulse response function analysis, we can see that the response of each variable on banking fragility in the short-term and long-term are not the same. ALR, ER, CPI, LDR and QR not only cause the banking fragility fluctuate in the short term, but also make the banking fragility stable at a level in the long wave. FER and M2 have some influence on banking fragility in the short run; when the impact of banking fragility vanishes, it will return to the original level. Namely these variables on banking fragility have no long-term effect. In addition, the effect of BLR on banking fragility is little in the short time. Therefore, the variables on the banking fragility have the short-term effect and long-term effect, and the management on banking fragility should choose different tools. When economic trend have been taken comprehensive consideration, the bank and its regulators think economic situation is only temporary, FER and M2 can be adjusted to improve the banking fragility; If the economy is in the stable state, then we can choose to adjust ALR, LDR, CPI, ER and QR which have long-term effects on banking fragility to improve it.

\section{Banking Fragility is Affected by Internal Factors and Macroeconomic Situation}

Most of the time China's banking fragility is relatively independent and its contributing factors are mainly from the banking system. But when the external economic environment fluctuates, the impact cannot be ignored. Therefore, in order to avoid shock from internal and external factors on bank fragility, the bank should establish a perfect risk management system to resist risks. In addition, banks should actively innovate different financial products to form a comprehensive, diversified product system. It can not only meet different needs of customers, but also disperse operation risk.

\section{REFERENCES}

[1] J. L. Huang, Financial Liberalization and Financial Fragility, Beijing: Chinese City Press, 2001.

[2] M. Zheng, The Theory of Financial Fragility, Beijing: China Financial Publishing House, 2007

[3] Q. Q. Lin, Financial Engineering, Beijing: Renmin University of China press, 2005

[4] D. K. Detragiache, "The determinants of banking crises in developed countries," IMF Staff Papers, 1998, vol. 45.

[5] T. M. Gao, Econometric Analysis and Modeling, Beijing: Tsinghua University press, 2009

[6] Y. Y. Li and R. Liu, Statistical Analysis and Application of Eviews, Beijing: Publishing House of Electronics Industry, 2013.

[7] S. C. Pan, Econometrics Intermediate Tutorial, Beijing: Tsinghua University Press, 2012 
[8] J. A. Kregal, "Margins of safety and weight of the argument in generating financial fragility," Journal of Economics, Cambridge University Press, 1997 , no. 2, p. 80.

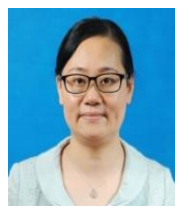

Lingjuan Xu was born in Jiangsu in 1971. She received her bachelor of engineering from Nanjing University of Aeronautics and Astronautics since 1995 to 1999; she received her master of management from College of Economics and Management, Nanjing University of Aeronautics and Astronautics since 1999 to 2002; She received her doctor of management from College of Economics and Management, Nanjing University of Aeronautics and Astronautics since 2003 to 2010 . The major field of study is corporate finance, stock investment and so on.

She has been an associate professor in Nanjing University of Aeronautics and Astronautics since 2008 and has been a lecturer form 2002 to 2007. Previous publications include research on S\&T business incubator performance management and evaluation in China (Beijing: China Science Press,2016); Comparative Study and Evaluation of S\&T Business Incubator Development Ability in Yangtze River Delta-Based on Survey Data of Jiangsu, Zhejiang, and Shanghai (Nanjing: Journal of Nanjing University of Aeronautics and Astronautics,2015); Analysis of
Influential Factors for investors' Stock Fund Performance in China (Nanjing: Academic Journal of Interdisciplinary Study, 2013). Her current research interests is in regional economic and financial management.

Ms. Xu has been a member of Financial Research Institute Nanjing University of Aeronautics and Astronautics since 2008. What's more, She has many honors such as award for excellent teaching of "A wonderful lesson", award for excellent teaching courseware (The Third Prize) and award for "My Favourite Teacher". 